\title{
Impact of Planetary Wave Reflection on Tropospheric Blocking over the Urals-Siberia Region in January 2008
}

\author{
Debashis NATH and Wen CHEN* \\ Center for Monsoon System Research, Institute of Atmospheric Physics, Chinese Academy of Sciences, Beijing 100190
}

(Received 24 March 2015; revised 28 July 2015; accepted 20 August 2015)

\begin{abstract}
Planetary wave reflection from the stratosphere played a significant role in changing the tropospheric circulation pattern over Eurasia in mid-January 2008. We studied the 2008 event and compared with composite analysis (winters of 2002/2003, 2004/2005, 2006/2007, 2007/2008, 2010/2011 and 2011/2012), when the downward coupling was stronger, by employing time-lagged singular value decomposition analysis on the geopotential height field. In the Northern Hemisphere, the geopotential fields were decomposed into zonal mean and wave components to compare the relative covariance patterns. It was found that the wavenumber 1 (WN1) component was dominant compared with the wavenumber 2 (WN2) component and zonal mean process. For the WN1 field, the covariance was much higher (lower) for the negative (positive) lag, with a prominent peak around +15 days when the leading stratosphere coupled strongly with the troposphere. It contributed to the downward coupling due to reflection, when the stratosphere exhibited a partially reflective background state. We also analyzed the evolution of the WN1 anomaly and heat flux anomaly, both in the troposphere and stratosphere, during JanuaryMarch 2008. The amplitude of the tropospheric WN1 pattern reached a maximum and was consistent with a downward wave coupling event influenced by the stratospheric WN1 anomaly at $10 \mathrm{hPa}$. This was consistent with the reflection of the WN1 component over Eurasia, which triggered an anomalous blocking high in the Urals-Siberia region. We further clarified the impact of reflection on the tropospheric WN1 field and hence the tropospheric circulation pattern by changing the propagation direction during and after the event.
\end{abstract}

Key words: planetary wave reflection, singular value decomposition (SVD), Eliassen-Palm (EP) flux, blocking, circulation

Citation: Nath, D., and W. Chen, 2016: Impact of planetary wave reflection on tropospheric blocking over the Urals-Siberia region in January 2008. Adv. Atmos. Sci., 33(3), 309-318, doi: 10.1007/s00376-015-5052-4.

\section{Introduction}

In recent decades, several studies have related tropospheric variability with the downward propagation of stratospheric anomalies through planetary wave reflection (Kodera et al., 2008). Due to the gradual increase in atmospheric pressure downward, the reflected component gets attenuated faster and its impact is considered to be minimal on the tropospheric regime. The theory of planetary wave reflection on tropospheric fields was initially proposed by Hines (1974) and Geller and Alpert (1980). Later, several authors discussed the coupling processes and downward propagation in the light of Northern Annular modes (Baldwin and Dunkerton, 1999, 2001), wave-mean flow interaction (Baldwin and Dunkerton, 2001; Christiansen, 2001) and anomalous propagation of the mean zonal wind field (Kodera et al., 1990; Kuroda and Kodera, 1999; Christiansen, 2000) down to the troposphere. Perlwitz and Graf (2001) and Perlwitz and Harnik $(2003,2004)$ statistically described the vertical

\footnotetext{
* Corresponding author: Wen CHEN

Email: cw@ post.iap.ac.cn
}

coupling of the wavenumber 1 (WN1) and wavenumber 2 (WN2) components downward with the tropospheric height fields. In winter the stratosphere is either reflective or nonreflective based on the strength of the polar vortex (Perlwitz and Harnik, 2004). The WN1 and zonal mean component play a major role when the background is reflective. Furthermore, employing time-lagged correlation analysis, Perlwitz and Harnik (2004) explained the gradual tilt in phase of the WN1 regression pattern (leading mode) vertically upward. With negative time lag the tilt is westward, but with positive lag it is eastward, and this feature is consistent with the downward propagation of planetary waves due to reflection.

Shaw et al. (2010) described the characteristics of downward wave coupling between the stratosphere and troposphere, using the 40-year ECMWF (European Centre for Medium-Range Weather Forecasts) reanalysis dataset. Employing cross-spectral correlation analysis and wave geometry diagnostics, they found that the downward WN1 coupling occurs both in the presence of a vertical reflecting surface in the mid-to-upper stratosphere and a high-latitude meridional waveguide in the lower stratosphere. They also discussed the 
importance of the seasonal cycle of the wave geometry for the proper representation of downward wave coupling between the stratosphere and troposphere, both in the Northern and Southern Hemisphere. In a separate study, Shaw and Perlwitz (2013) statistically investigated the life cycle of Northern Hemisphere wave coupling events and found that it occurs over a period of 28 days. Furthermore, they showed that during the downward coupling process, there is a transition in stratospheric WN1 heat flux, from positive to negative, and the WN1 phase tilts from westward to eastward. Shaw et al. (2014) established a new dynamical metric of troposphere-stratosphere coupling, based on extreme stratospheric planetary-scale wave heat flux events.

Coughlin and Tung (2005) demonstrated the possibility of wave reflection in the context of major sudden stratospheric warming (SSW) events and discussed its impact on the tropospheric weather regime (Nath et al., 2013). They illustrated the changes in the tropospheric WN1 field in response to the reflected component from the stratosphere. Separately, Kodera et al. (2008) related the occurrence of an extreme cold event in March 2007 over the northeast coast of the North American continent, to the upward and reflected component of planetary waves over Eurasia and the North American sector, respectively. During an SSW event in 1984-85, Kodera and Chiba (1995) investigated the changes in circulation pattern due to downward and equatorward propagation of midlatitude planetary waves to the troposphere. Geopotential anomalies that propagate downward to the troposphere have a significant impact on the tropospheric weather regime, particularly in non-reflective years (Perlwitz and Harnik, 2004). Perlwitz and Harnik (2004) categorized the reflective and non-reflective basic states for planetary WN1 reflection based on the zonal-mean zonal wind difference between 2 and $10 \mathrm{hPa}$, averaged over $58^{\circ}-74^{\circ} \mathrm{N}$ and over time. The reflective basic state corresponds to a negative index with the polar night jet peaking in the mid-stratosphere; whereas, for the non-reflective state, the zonal wind increases with increasing height. The planetary waves propagate upward along the stratospheric westerly jet, weakening the polar night jet in the upper stratosphere. This inhibits further propagation of the planetary waves high up in the stratosphere and it reflects back to the troposphere. During reflective winters the stratospheric signals are weak and get attenuated above the tropopause (Perlwitz and Harnik, 2004). Moreover, in strong polar vortex winters, the WN1 reflection pattern is more prominent (Perlwitz and Graf, 2001); whereas, in weak vortex years, stratosphere-troposphere coupling is relatively strong (Baldwin and Dunkerton, 1999, 2001).

Here, we considered a specific case in the pre-warming phase of a major SSW event in January 2008. As reported previously (Hui, 2009; Zhou et al., 2009; Nath et al., 2014), in January and early February 2008, parts of Eurasia and China experienced extreme cold events, snowfall and freezing rain, particularly in the southern part of China. These phenomena caused excessive damage, disruption and major infrastructure loss, resulting in broken power transmission lines and chaotic traffic conditions (Zhou et al., 2009). China experienced sub- stantial economic losses of 53.8 billion RMB due to freezing rain alone. Between 10 January and 2 February 2008 there were four episodes of severe and persistent snow over the Yangtze River basin, South China, and Southwest China. The 2008 event was the coldest event since at least 1979, bringing about 107 casualties, according to the Ministry of Civil Affairs.

Zhou et al. (2009) indicated the key factors as the occurrence of a persistent blocking high over Siberia, as well as strong and persistent southwesterly flow, which triggered moisture advection from the Bay of Bengal to southerncentral China, and the formation of a deep inversion layer in the lower troposphere. Furthermore, Hui (2009) attributed these adverse meteorological conditions with abnormal circulation anomalies at high latitudes. In a separate study, Nath et al. (2014) demonstrated that when the stratospheric basic state is partially reflective, a wave packet emanating from Baffin Island/the coast of Labrador propagates eastward, equatorward and reflects back over central Eurasia and parts of China, which in turn triggers the advection of cold wind from the northern part of the boreal forest region and Siberia to the subtropics. The extraordinary persistence of this particular cold event has been linked with anomalous blocking high over the Urals-Siberia region.

Despite many previous studies having investigated the key factors (like tropospheric blocking) that triggered the extreme cold event in January 2008, none explored the causative mechanism underpinning the occurrence of the anomalous blocking high over the Urals-Siberia region. In the present study, we performed lagged correlation analysis to understand the respective contribution of the wave (WN1 and WN2) and zonal mean flow in conjunction with stratospheretroposphere coupling processes. By analyzing the squared covariance between the stratospheric and tropospheric height field, we identified the key dates in January 2008 when the impact of the stratospheric basic state on the troposphere was at a maximum (or vice versa). We also compared the singular value decomposition (SVD) pattern of the 2008 event with the composite mean pattern, which included several winters for which downward wave coupling has been reported. Based on Shaw and Perlwitz (2013), Kodera et al. (2013), and Dunn-Sigouin and Shaw (2015), we chose the winters of 2003, 2005, 2007, 2008, 2011 and 2012 for the composite analysis. We also estimated the changes in the tropospheric WN1 field and hence the tropospheric circulation, during and after the event. Furthermore, we clarified the role of planetary wave reflection on the tropospheric circulation pattern and formation of strong Urals-Siberia blocks.

\section{Data and methodology}

\subsection{Data}

Daily mean ECMWF Interim Reanalysis (ERA-Interim) data (Uppala et al., 2008; Dee et al., 2011) were used for potential vorticity, geopotential height, zonal wind, meridional wind, and temperature. The individual parameters were 
archived from December to April from 2002/2003 to 2011/ 2012. The ERA-Interim data are available at 37 pressure levels from $1000 \mathrm{hPa}$ to $1 \mathrm{hPa}$, with a horizontal resolution of $1.5^{\circ} \times 1.5^{\circ}$.

\subsection{Methodology}

\subsubsection{Time-lagged SVD}

Time-lagged SVD analysis was used to establish the dynamical connection between the geopotential height fields in the stratosphere and troposphere (Perlwitz and Harnik, 2003, 2004). The leading coupled modes were extracted from the spatiotemporal structures of the geopotential height perturbations. We performed the analysis and estimated the covariance with the temporal series of two height fields at individual time lags separately. The height perturbations were arranged such that each column was the time series for a given location. Based on Perlwitz and Harnik (2003, 2004), the geopotential height fields could be expanded orthogonally, which can be expressed as

$$
\begin{gathered}
H_{1}(x, t)=\sum_{n=1}^{N} u_{n}(x) a_{n}(t), \\
H_{2}(x, t+\tau)=\sum_{n=1}^{N} v_{n}(x) b_{n}(t+\tau),
\end{gathered}
$$

where $H_{1}$ and $H_{2}$ are the geopotential height fields at time $t$ and $t+\tau, u_{n}$ and $v_{n}$ are the singular matrices, $N$ is the number of modes, and $s_{n}^{2}$ is the square of $n$th singular value of the covariance matrix between $H_{1}$ and $H_{2}$-constructed by taking the covariance between the two expansion coefficients $a(t)$ and $b(t+\tau)$. The coupled modes are arranged with increasing $n$ and decreasing covariance. $S$ is the total squared covariance between the two coupled fields:

$$
S=\sum_{n=1}^{N} s_{n}^{2} .
$$

In our analysis, the reference height was fixed at $10 \mathrm{hPa}$ and the SVD analysis was performed with the levels descending downward from $10 \mathrm{hPa}$ to $1000 \mathrm{hPa}$ at different lags $(\tau)$ in time lags from -30 to +30 days, i.e., 61 time lags. At the reference height, the time span from 1 January to 30 March, i.e., 90 days, remained fixed; whereas, the other levels were shifted temporally by -30 to 30 days with an interval of 1 day. Thus, positive lags indicated that the stratosphere was leading and the troposphere was lagging, and vice versa for negative lags. In order to detect the time lag at which the dynamical relation between $H_{1}$ and $H_{2}$ was maximal, correlation coefficients between the leading coupled modes, $a_{1}$ and $b_{1}$, were computed for each of the 61 SVD analyses.

To understand the contribution of wave processes and the zonal mean field, SVD analysis was performed between zonal mean fields, the eddy field (i.e., deviation from the zonal mean), and the WN1 and WN2 height fields, separately. Prior to the SVD analysis, we removed the mean seasonal cycle and multiplied the data by the square root of the density and the cosine of latitude along the altitude and latitude, respectively. In order to concentrate on the intra-annual variability and exclude the influence of a trend in the covariance, the annual mean averages of the geopotential height fields were removed. Although we did not use any temporal filtering, strong spatial filtering was applied in the wavenumber domain, both for the $H_{1}$ and $H_{2}$ zonal mean fields. To extract the WN1 and WN2 components from the geopotential height perturbations, we applied the least squares fitting (LSF) method for spectral analysis. This method was used to fit a set of zero mean observations, $y_{i}$, at times $i=1,2, \cdots, N$, to the equation given by

$$
y_{i}=(A+B) \cos \left(2 \pi w \lambda_{i}\right),
$$

where $w$ is the wavenumber, $\lambda_{i}$ represents the longitudes, and $A$ and $B$ are the coefficients to be fitted. The individual wave components were then computed using the empirical relation

$$
Y_{s}=A \sin \left(w \lambda_{i}+\phi\right),
$$

where $A$ is the amplitude and $\phi$ is the phase, estimated by means of LSF analysis.

In order to estimate a grid size independent measure of $S$, the mean squared covariance, $C$, between two grid points of the $H_{1}$ and $H_{2}$ fields can be defined as

$$
C=\sqrt{\frac{S}{m_{1} m_{2}}},
$$

where $m_{1}$ and $m_{2}$ are the grid points of $H_{1}$ and $H_{2}$ fields. Here, we interpolated the height fields to $4.5^{\circ}$ in longitude and $3^{\circ}$ in latitude and performed the SVD analysis between $30^{\circ}$ and $85^{\circ} \mathrm{N}$. Hence, $m_{1}=m_{2}=1600$, corresponding to 80 and 20 longitudinal and latitudinal grid points, respectively.

\subsubsection{Blocking index}

Midlatitude blocking is characterized by local formation of anomalous easterly flow due to the blocking of the westerly jet and mass transfer from high- to midlatitudes (Namias and Clapp, 1951; Treidl et al., 1981; Barriopedro et al., 2006). In general, the blockings are quasi-stationary patterns that persist for several weeks and have a significant impact on rainfall redistribution and the occurrence of extreme weather events at regional scales. A persistent blocking pattern also induces strong advection of polar air, southward, leading to extreme cold weather in boreal winter months (Nath et al., 2014). For January 2008, Zhou et al. (2009) and Nath et al. (2014) reported an anomalous and persistent blocking pattern in the Urals-Siberia region. The frequency of blocking exceeded the climatological high over $55^{\circ}-70^{\circ} \mathrm{E}$. We computed the blocking index from Tibaldi and Molteni (1990), with the additional criteria proposed by Barriopedro et al. (2006). The $500 \mathrm{hPa}$ geopotential height gradients in the north and south (GHGN and GHGS) (units: gpm/latitude) were simultaneously computed using the following expressions:

$$
\begin{aligned}
\mathrm{GHGN} & =\frac{H\left(\lambda, \theta_{N}\right)-H\left(\lambda, \theta_{0}\right)}{\theta_{N}-\theta_{0}}, \\
\mathrm{GHGS} & =\frac{H\left(\lambda, \theta_{0}\right)-H\left(\lambda, \theta_{S}\right)}{\theta_{0}-\theta_{S}},
\end{aligned}
$$




$$
\begin{aligned}
\theta_{\mathrm{N}} & =78.0+\delta \\
\theta_{0} & =60.0+\delta \\
\theta_{\mathrm{S}} & =39.5+\delta \\
\delta & =-4.5,-3.0,-1.5,0.0,1.5,3.0,4.5 .
\end{aligned}
$$

where $H(\lambda, \theta)$ is the $500 \mathrm{hPa}$ geopotential height, $\delta$ is the shift in latitude, GHGS is the measure of the zonal geostrophic wind component, and GHGN is imposed to exclude the non-blocked flows (Barriopedro et al., 2006). An arbitrary longitude was considered to be blocked if the following conditions were satisfied:

$$
\begin{gathered}
\text { GHGN }<-10 \\
\text { GHGS }>0 \\
H\left(\lambda, \theta_{0}\right)-\overline{H\left(\lambda, \theta_{0}\right)}>0 .
\end{gathered}
$$

To identify the potential blocks, a three-day running mean filter was applied at each longitude.

\section{Results and discussion}

\subsection{Covariability of the stratospheric and tropospheric height fields}

First, we compared the relative dominance of the zonal mean and the height wave fields for January-FebruaryMarch (JFM), as obtained from the SVD analysis. The squared covariance between the $10 \mathrm{hPa}$ and various pressure levels $(10$ to $1000 \mathrm{hPa})$ at different time lags $(-30$ to 30 days), for the zonal mean, deviation from the zonal mean,
WN1 height, and WN2 height are shown in Fig. 1. The composite mean patterns for six winters (2002/2003, 2004/2005, 2006/2007, 2007/2008, 2010/2011 and 2011/2012) when the downward coupling was stronger is shown in the upper panels, Figs. 1a-d. The lower panels, Figs. 1e-h, exhibit the SVD patterns for the 2008 event, in order to compare the consistency with the composite mean pattern. For the zonal mean field (Figs. 1a and e), in the positive time lag (stratosphere leads), the covariance is stronger and extended (longer time scale) in the lower stratospheric heights. Meanwhile, in the negative time lag (troposphere leads), the covariance is relatively weaker and less persistent below $20 \mathrm{~km}$. In the present analysis, the covariability is maximum and dominant for the leading coupled mode (first), because it explains around $80 \%$ of the squared covariance in all height regions.

Figures $1 \mathrm{~b}$ and $\mathrm{f}$ depict the covariability of the deviation from the zonal mean field for the composite and 2008 case, respectively. Unlike the zonal mean field, the covariance is relatively stronger for the negative and positive time lag in the mid-tropospheric $(3-11 \mathrm{~km})$ and lower stratospheric $(>16$ $\mathrm{km})$ heights, respectively. The mid-tropospheric covariance is well extended over all time lags ( -30 to 30 days), with a maximum around \pm 15 days; whereas, in the lower stratospheric heights, the covariance is biased towards the positive side, with peaks around $0-5$ day $(>20 \mathrm{~km})$ both for the composite and 2008 case. The zonal deviation field includes the contribution of various wave processes, and at given latitudes the WN1 and WN2 components were separated out using the LSF method, described in section 2.2.1.

As is clear from Fig. 1c, the WN1 covariance $(\sim 300$ (a) Zonal Mean Composite

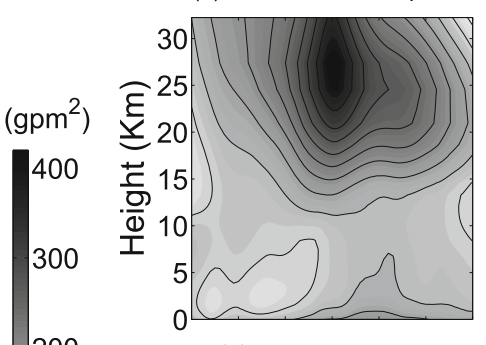

(e) Zonal Mean, 2008

$-100$

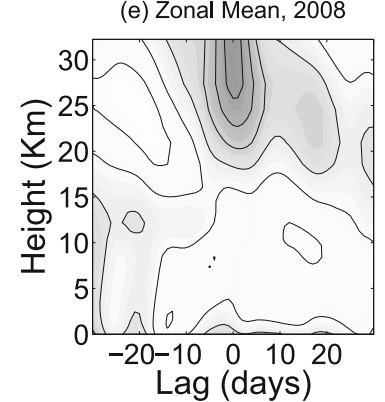

(b) Anomaly Composite

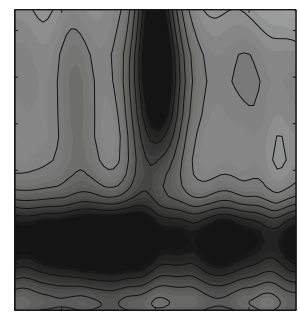

(f) Anomaly, 2008

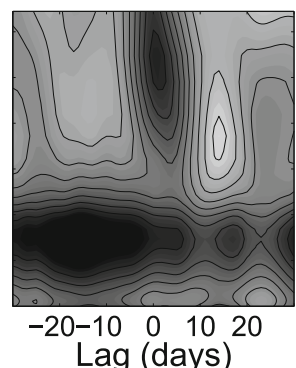

(c) WN1 Composite

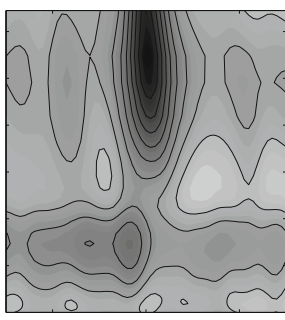

(g) WN1, 2008

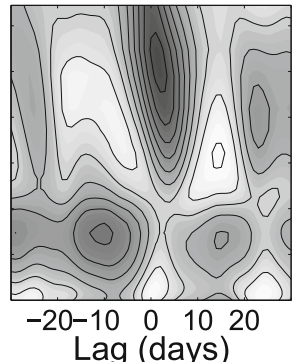

(d) WN2 Composite

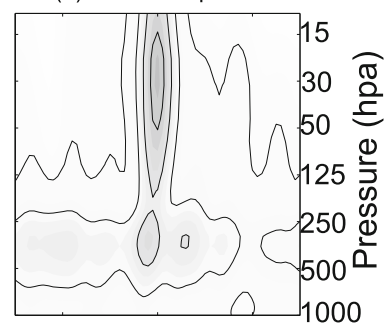

(h) WN2, 2008

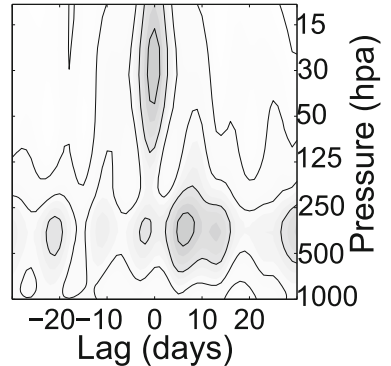

Fig. 1. The covariance (units: $\mathrm{gpm}^{2}$ ) between the geopotential height fields at $10 \mathrm{hPa}$ and all pressure levels between 1000 and $10 \mathrm{hPa}$, for time lags ranging from -30 to 30 days: (a-d) the covariance of the zonal mean, deviations from the zonal mean, WN1 height, and WN2 height, respectively, for the composite winter of 2002/2003, 2004/2005, 2006/2007, 2007/2008, 2010/2011 and 2011/2012; (e-h) the same, but for 2008 case. A positive time lag indicates that the stratospheric field is leading. The left and right axes represent the height (units: km) and pressure (units: hPa), respectively. 
$\mathrm{gpm}^{2}$ ) for the composite case compares well with the deviation from the zonal mean field $\left(\sim 400 \mathrm{gpm}^{2}\right)$. We can see the humps with larger covariance at the lags of -3 days (troposphere leads) and +15 days (stratosphere leads) in the WN1 field. The features are quite consistent with the 2008 case (Fig. 1g), at least on the positive side, with stronger downward coupling at +15 days' lag. Another noticeable feature is the intense downward coupling due to the WN1 field, with a persistent covariance pattern down to the surface at +15 days' lag. But, for the WN2 field, both the composite and 2008 event (Figs. 1d and h) exhibit much weaker covariance $\left(\sim 100 \mathrm{gpm}^{2}\right)$ throughout the height range. The WN2 covariance, meanwhile, although weaker than WN1, exhibits a dominant peak at around +5 days' lag (stratosphere leads) and $400 \mathrm{hPa}$, both for the composite and 2008 event. Perlwitz and Harnik (2004) linked the planetary wave reflection with the humps in the positive lags when the basic state of the stratosphere was reflective. In Nath et al. (2014), it was shown that, apart from the zonal mean reflective index, the longitudinal variation too has a severe impact on regional weather extremes, and the concept of a partially reflective stratospheric background state was introduced. All six winters chosen for the composite analysis - based on Shaw and Perlwitz (2013), Kodera et al. (2013) and Dunn-Sigouin and Shaw (2015) - except 2006/2007, exhibit a partially reflective stratospheric background state. Therefore, during these years, when the downward coupling was stronger, the relative dominance of the WN1 covariance from the stratosphere should have had a significant impact on the tropospheric circulation pattern.

To further elucidate the relative contribution of the zonal mean and the WN1 field, we plotted the covariance for the zonal mean $(850 \mathrm{hPa})$ and WN1 $(400 \mathrm{hPa})$ field, both for the composite (Fig. 2a) and 2008 event (Fig. 2b). As can be seen, for the WN1 field, the covariance is much higher (lower) for the negative (positive) lag, with a prominent peak at around +15 days when the leading stratosphere coupled strongly with the troposphere. Meanwhile, in the negative lag (troposphere leads), the peaks are prominent at lags of -4 days and -10 days for the composite and 2008 case, respectively. This difference is obvious and can be attributed to the difference in upward wave propagation during the six winters included in the composite analysis. The winters were chosen based on Shaw and Perlwitz (2013), Kodera et al. (2013) and Dunn-Sigouin and Shaw (2015), when downward coupling was prominent, irrespective of any precursory upward wave propagation events. For example, according to Dunn-Sigouin and Shaw (2015, Table 1), there were three downward propagating events, on 6 February, 25 February and 31 March 2003, but the upward propagation occurred long before the downward coupling events on 14 January 2003. Similarly, for the 2008 case, there is no upward propagation prior to the wave reflection event. In the zonal mean field, the covariance is much lower compared with the WN1 field, and the absence of any significant maxima, either in the positive or negative time lag, is prominent. (a) Composite of all Events
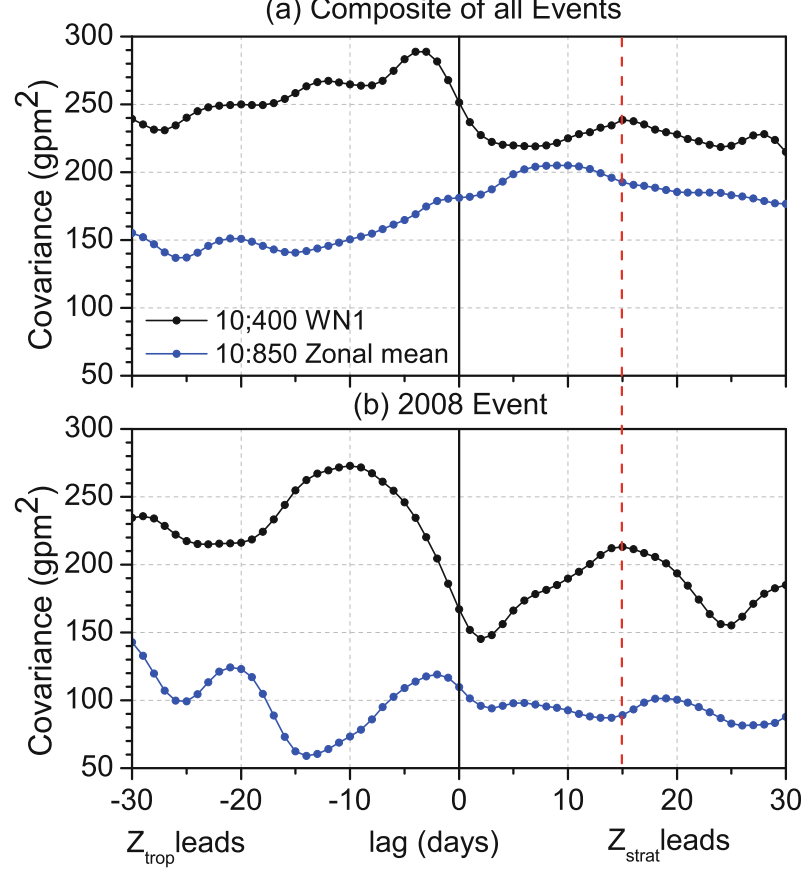

Fig. 2. The covariance $\left[\mathrm{gpm}^{2}\right]$ between the tropospheric and stratospheric height fields at $30^{\circ}-85^{\circ} \mathrm{N}$ for time lags between -30 and 30 days for the composite winters (upper panel) and 2008 case (bottom panel) between the leading coupled mode. Blue line: covariability between $10 \mathrm{hPa}$ and $850 \mathrm{hPa}$ zonal mean fields; Black line: covariability between 10 and $400 \mathrm{hPa}$ height WN1 fields. A positive time lag indicates that the stratospheric field is leading. The maxima are significant at least to the $99 \%$ confidence level.

\subsection{Evolution of WN1 height and heat flux for the 2008 event}

Based on the SVD timed lagged analysis, we identified that - both in the composite and 2008 case-downward coupling due to reflection was strongest at +15 days' lag. This corresponds to 15 of January as the key date for the 2008 case study. The evolution of the high-latitude WN1 pattern can be illustrated using a Hovmöller plot. Figure 3 a shows the total WN1 pattern averaged between $60^{\circ}$ and $80^{\circ} \mathrm{N}$ at $400 \mathrm{hPa}$ (black contours) and $10 \mathrm{hPa}$ (coloring) as a function of longitude and time from -20 to +20 days (15 January as the start date). Downward WN1 coupling events clearly coincide with changes in the tropospheric wave pattern. In the first stage ( -20 to -10 days), the $400 \mathrm{hPa} \mathrm{WN1}$ pattern over the UralsSiberia region is very weak. During the second stage $(-10$ to 0 days), the amplitude of the $10 \mathrm{hPa}$ high-latitude WN1 pattern reaches a maximum and precedes the maximum amplitude at $400 \mathrm{hPa}$, which occurs during stage three (0 to10 days). The features are consistent with Shaw and Perlwitz (2013, Fig. 5). The amplitude of the $400 \mathrm{hPa}$ WN1 pattern reaches a maximum during the third stage and at the same time the pattern continues to move westward. Finally, in the fourth stage (10 to 20 days), the amplitude of the WN1 pattern decreases significantly and, overall, the wave pattern evolution is very consistent with a downward wave coupling 
(a) WN1 Evolution and Blocking Index

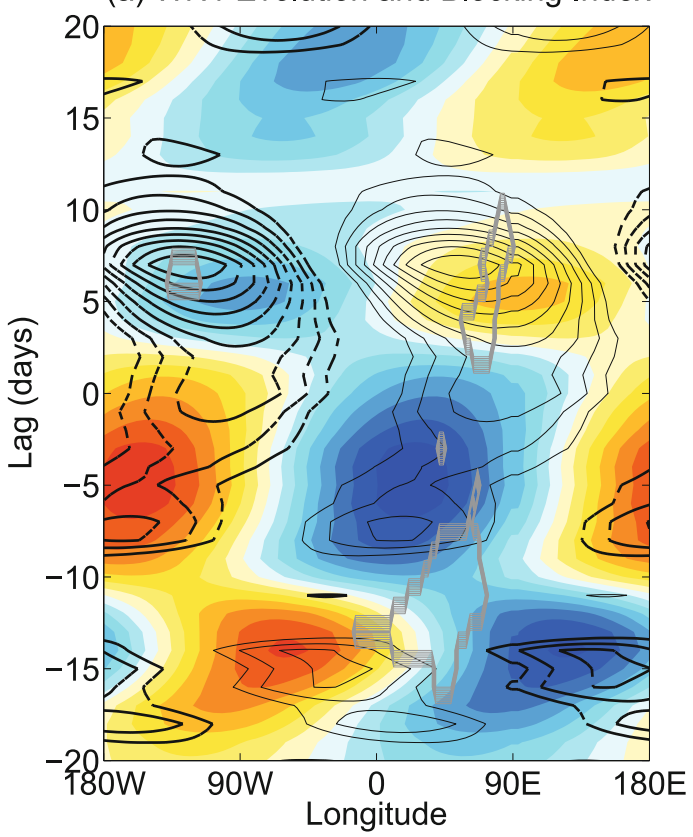

(b) WN1 Heat Flux Evolution and Blocking Index

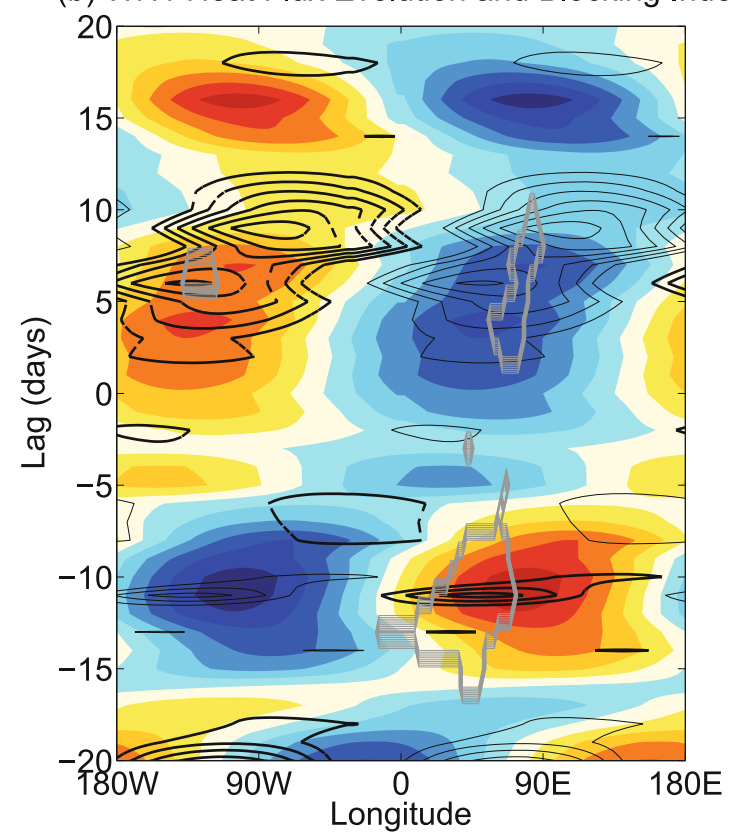

Fig. 3. (a) Evolution of the total $400 \mathrm{hPa}$ (black contours) and $10 \mathrm{hPa}$ (color shading) WN1 pattern averaged from $60^{\circ}$ to $80^{\circ} \mathrm{N}$ for the 2008 event as a function of time from -20 to 20 days and longitude. The contour interval is $10 \mathrm{~m}$, and the ranges are -100 to $100 \mathrm{~m}$ and -75 to $75 \mathrm{~m}$ for the black contours and color shading, respectively. (b) As in (a) but for the WN1 heat flux anomaly. The contour interval is $0.01 \mathrm{~m}^{2} \mathrm{~s}^{-2}$ and $0.003 \mathrm{~m}^{2} \mathrm{~s}^{-2}$, and the ranges are from -0.1 to $0.1 \mathrm{~m}^{2} \mathrm{~s}^{-2}$ and -0.018 to $0.018 \mathrm{~m}^{2} \mathrm{~s}^{-2}$ for the black contour and color shading, respectively. The bold dotted and light normal black contours in $(\mathrm{a}, \mathrm{b})$ represent the negative and positive anomalies, respectively. The longitude-time section of the blocking index (gray contour lines) is overplotted in both (a) and (b).

event: a stratospheric WN1 anomaly at $10 \mathrm{hPa}$ precedes a tropospheric WN1 anomaly at $400 \mathrm{hPa}$. All the features are highly consistent with Shaw and Perlwitz (2013, Fig. 5).

A downward coupling event due to reflection is linked with the transition of the heat flux anomaly (product of meridional wind and temperature anomaly) from positive to negative in the stratosphere (Shaw and Perlwitz, 2013). Therefore, we also plotted the evolution of the WN1 heat flux anomaly for the 2008 case (Fig. 3b). Like the WN1 anomaly, the heat flux pattern averaged between $60^{\circ} \mathrm{N}$ to $80^{\circ} \mathrm{N}$ at 400 $\mathrm{hPa}$ (black contours) and $10 \mathrm{hPa}$ (coloring) as a function of longitude and time from -20 to +20 days is shown. In the first stage ( -20 to -10 days), the heat flux anomaly in the stratosphere is strongly positive, particularly over the UralsSiberia region, which is indicative of an upward wave coupling precursor. Meanwhile, in the troposphere, there is no significant heat flux anomaly during this stage. In the second stage ( -10 to 0 days), the heat flux anomaly in the stratosphere changes sign from positive to negative. In addition, a positive heat flux anomaly starts to develop in the troposphere. In the third stage (0 to 10 days), the negative anomaly in the stratosphere attains its maximum, with subsequent development of a strong positive heat flux anomaly in the troposphere. The tropospheric maxima clearly lag the minima in the stratosphere. Finally, in the fourth stage (1020 days), the heat flux anomaly weakens, but remains negative in the stratosphere; while in the troposphere, it fades out completely. The features are highly consistent with Shaw and
Perlwitz (2013), completely describing the evolution of the WN1 anomaly during the downward wave coupling events.

\subsection{Urals-Siberia blocking index}

To illustrate the zonal propagation of planetary waves, Nath et al. (2014) computed the eddy component of Plumb fluxes (Plumb, 1985) in 3D space. From the vertical component of wave activity flux at $200 \mathrm{hPa}$, they showed that the reflection phenomena were more prominent from 10 to 19 January 2008. Furthermore, the upward propagation was stronger over the Labrador coast and Baffin Island. Whereas, the reflected components were prominent over the Eurasian continent and eastern parts of China. Upward and reflected fluxes were prominent in the upstream and downstream regions of the reflecting surfaces (Nath et al., 2014), respectively, indicating the impact of the polar jet stream, which preferentially guided the planetary waves (WN1) eastward and downward of the source region (Nath et al., 2014).

Several authors have delineated the role of blocking as a precursor to SSW events (Martius et al., 2009). Recently, Kodera et al. (2013) elucidated the relationship between stratospheric planetary wave reflection and blocking formation in the troposphere during SSW events. The upward propagation of the planetary waves in the pre-warming stage involves a Euro-Atlantic block; whereas, the downward propagation promotes the formation of Pacific blocking during the warming event. The longitude-time section of the blocking index were overplotted (gray contour lines) in both Figs. 3a 
10 hpa

(a) lag:-10 days,83\%

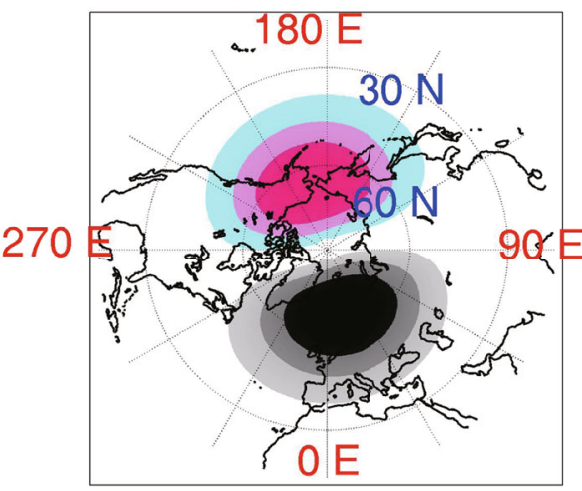

(b) lag:15 days,73\%

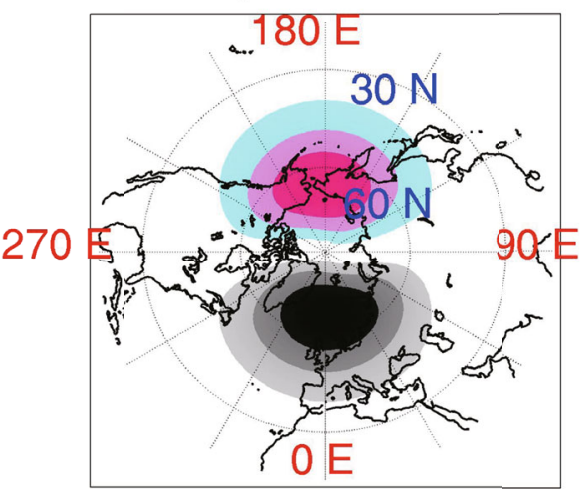

(gpm)

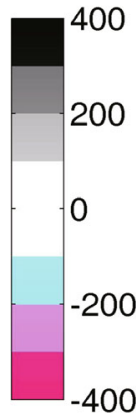

(d) lag:15 days,76\%

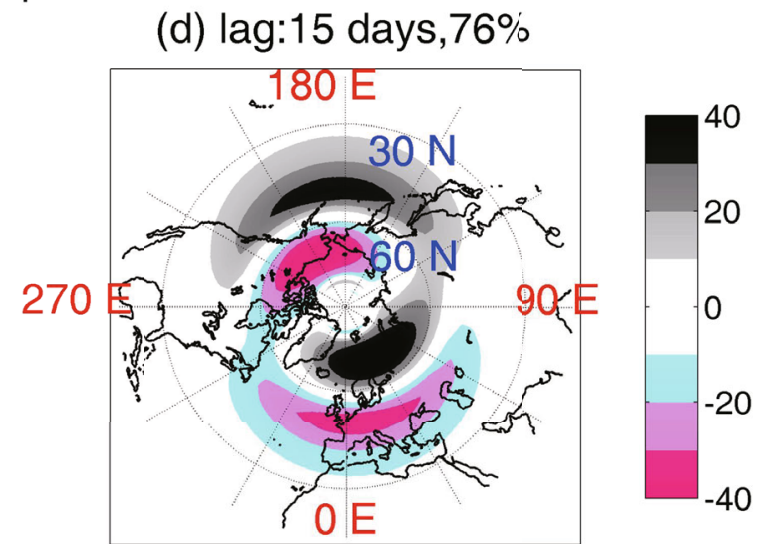

$400 \mathrm{hpa}$ (c) lag:-10 days, $69 \%$

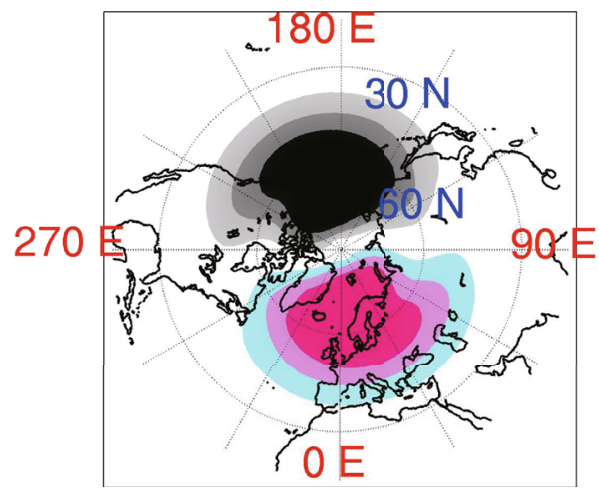

Fig. 4. Heterogeneous regression pattern (units: gpm) of the leading coupled mode of the (a, b) $10 \mathrm{hPa}$ and (c, d) $400 \mathrm{hPa}$ WN1 fields at time lags of (a, c) -10 days and (b, d) +15 days for the 2008 case. The color shading varies from -400 to $400 \mathrm{gpm}$ in (a, b) and from -40 to $40 \mathrm{gpm}$ in (c, d), with an interval of $40 \mathrm{gpm}$ and $4 \mathrm{gpm}$, respectively. These maps were constructed by regressing the time series of the $10 \mathrm{hPa}(400 \mathrm{hPa}) \mathrm{WN} 1$ fields onto the temporal expansion coefficients of the leading mode of $400 \mathrm{hPa}(10 \mathrm{hPa})$. The percentage in the title of the individual subplots indicates the variance accounting for the leading coupled mode.

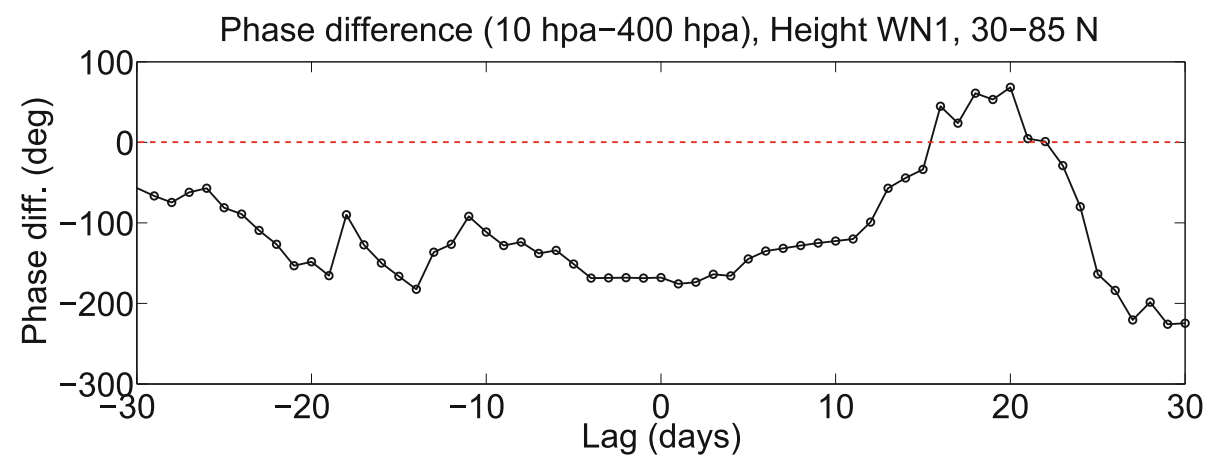

Fig. 5. Phase difference (degrees) between the associated WN1 regression patterns at $10 \mathrm{hPa}$ and $400 \mathrm{hPa}$, averaged over the latitudinal band of $30^{\circ}-85^{\circ} \mathrm{N}$, as a function of time lags. Negative and positive values indicate westward and eastward phase shifts with heights, respectively. The red line indicates zero phase difference.

and $\mathrm{b}$ to address the coincidence of the blocking event with tropospheric WN1 evolution due to reflection. The blocking index (dimensionless; contour lines) represents the zonal and temporal spread over which the mid-tropospheric flow is blocked, i.e., for which all three criteria [Eqs. (7a-c)] are satisfied simultaneously. A strong Urals-Siberia blocking is predominant in the third stage, when the amplitude of the 400 $\mathrm{hPa}$ WN1 pattern reaches its maximum value and the pattern continues to move westward. Consistently, the negative heat flux anomaly in the stratosphere attains its maximum with 


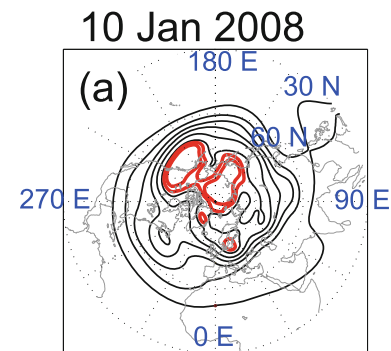

14 Jan 2008

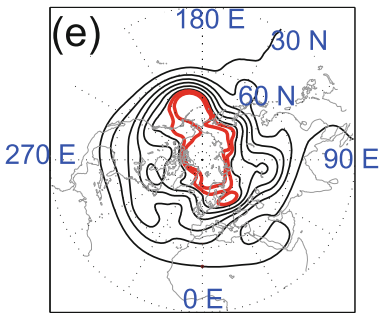

18 Jan 2008

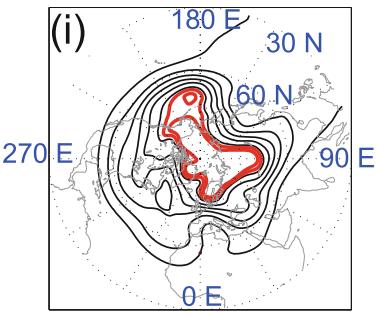

11 Jan 2008

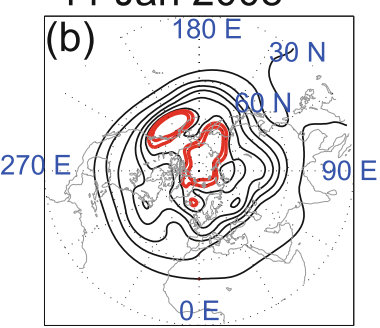

15 Jan 2008

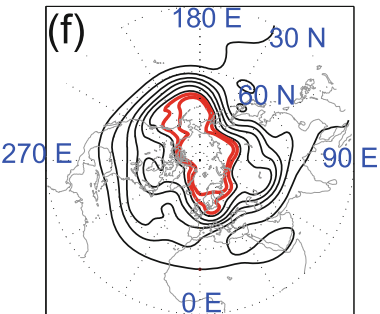

19 Jan 2008

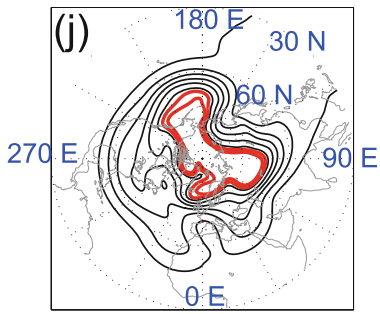

12 Jan 2008

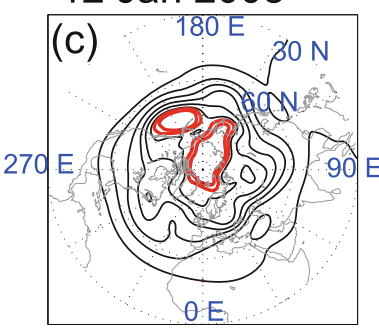

16 Jan 2008

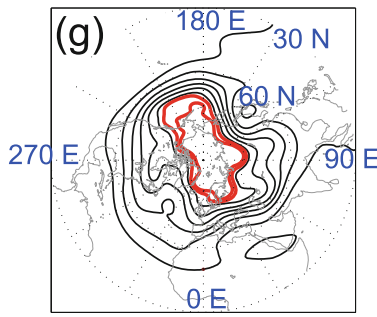

20 Jan 2008

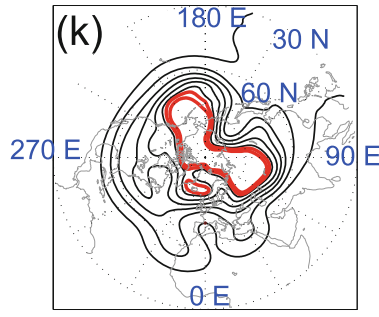

13 Jan 2008

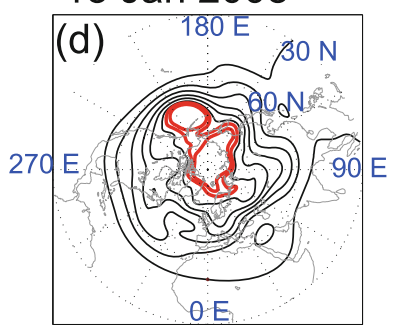

17 Jan 2008

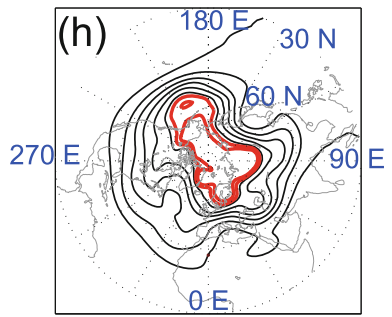

21 Jan 2008

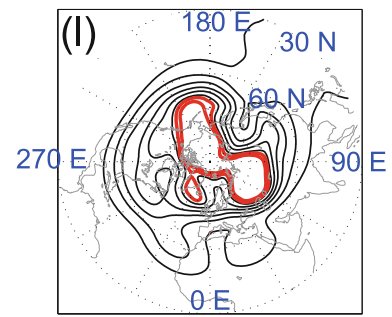

Fig. 6. Daily $500 \mathrm{hPa}$ geopotential height maps from (a-1) 10-21 January 2008, respectively. The contours are from 5100 to 5900 gpm, with an interval of $60 \mathrm{gpm}$. Heights between 5100 to $5160 \mathrm{gpm}$ are marked with red contours.

subsequent development of a strong positive anomaly in the troposphere. This feature is analogous to the formation of an anomalous Urals-Siberia blocking high, downstream of the reflected fluxes (Nath et al., 2014) from 15 to 25 January. The blocking index was calculated using Eqs. (7a-d). Furthermore, it is clear from the Eliassen-Palm (EP) flux vector (Nath et al., 2014) that, around mid-January, the upward component of the high latitude wave guide was very weak; it was only the downward component that could have contributed to the development of the blocking high over the Urals-Siberia region.

\subsection{Heterogeneous regression patterns and tropospheric circulation}

Perlwitz and Graf (2001) showed that the stratospheric $\mathrm{WN} 1$ field $(50 \mathrm{hPa})$ leads the tropospheric WN1 field (500 $\mathrm{hPa}$ ) by 6 days; whereas, using time-lagged SVD analysis, Perlwitz and Harnik (2004) investigated the close relationship between the $500 \mathrm{hPa}$ (tropospheric field) and $50 \mathrm{hPa}, 30$ $\mathrm{hPa}$ and $10 \mathrm{hPa}$ (stratospheric field) levels, individually, in composites of all winter seasons. Again, Kodera and Chiba (1995) showed that, in the troposphere, the circulation pattern changed significantly in relation to SSW events during 1984-85. They also linked the generation of anomalous cold surges and synoptic-scale eddies due to changes in the meridional propagation of tropospheric waves around the $500 \mathrm{hPa}$ level. They further suggested that the changes in planetary wave structure could trigger enhanced baroclinic waves in the troposphere.

In the present study, we expected the heterogeneous regression pattern at dominant positive and negative time lags to exhibit gradual eastward and westward shift, in phase, along the vertical direction, respectively. As discussed in section 3.1, strong downward coupling due to the WN1 field with a persistent covariance (between $10 \mathrm{hPa}$ and $400 \mathrm{hPa}$ ) pattern down to the surface at lags of -10 days (troposphere leads) and +15 days (stratosphere leads) is noticeable in Fig. 2a. The two maxima exceed at least the $99 \%$ confidence level. The strength of coupling between the modes at different time lags is well illustrated by the heterogeneous regression patterns of the WN1 field at $400 \mathrm{hPa}$ and $10 \mathrm{hPa}$, constructed when the $400 \mathrm{hPa}(10 \mathrm{hPa})$ field leads the $10 \mathrm{hPa}(400 \mathrm{hPa})$ at a time lag of -10 days $(+15$ days $)$. The regression patterns in the lag of -10 days ( +15 days), both for $10 \mathrm{hPa}$ and 400 $\mathrm{hPa}$, are plotted in Figs. $4 \mathrm{a}$ and $\mathrm{b}$ ( $4 \mathrm{c}$ and d), respectively, to understand the evolution of the entire process. The regression patterns associated in the negative and positive time lags exhibit completely different structure. At -10 days' lag, the ridge of the WN1 field at $10 \mathrm{hPa}$ shifts westward with respect to the $400 \mathrm{hPa}$ level; whereas, at +15 days' lag, the regression pattern at $400 \mathrm{hPa}$ level shifts eastward relative to the $10 \mathrm{hPa}$ level. This eastward shift in phase of the WN1 field 
at $400 \mathrm{hPa}$ is consistent with the downward reflected wave. Since the square of the correlations represents the variance explained locally, the leading coupled mode accounts for up to $\sim 70 \%$ and more of the variance in the region of large amplitude. The variance, in terms of percentage, is noted in the titles of the individual subplots. In addition, at $400 \mathrm{hPa}$ and for positive time lags, the phase tilts largely eastward with increasing latitude. We further compared the phase shift (degrees) between the WN1 field at the $10 \mathrm{hPa}$ level and 400 $\mathrm{hPa}$ level; the differences at different time lags are plotted in Fig. 5. A continuous westward phase shift (negative) of the $\mathrm{WN} 1$ ridge, averaged over the latitude band of $30^{\circ}-85^{\circ} \mathrm{N}$, is clearly visible for all negative time lags; whereas, after +10 days' lag, the phase shift tends towards the zero mark, becomes eastward (positive) after +15 days' lag, and westward again from +22 days' lag.

To further establish the link between anomalous blocking patterns in the Urals-Siberia region and the tropospheric WN1 field due to changes in circulation pattern, the daily march of the $500 \mathrm{hPa}$ geopotential height fields from 10 to 21 January are plotted in Fig. 6. The contours from 5100 to $5900 \mathrm{gpm}$, with an interval of $60 \mathrm{gpm}$, are shown, and the geopotential height between 5100 and 5160 gpm is marked in red. Up until 12 January, the WN1 pattern in the troposphere is not very clear and is mainly concentrated at high latitudes. But, from 13 January onward, the WN1 pattern starts to develop slowly and exhibit a meridionally elongated pattern stretching from the Bering Sea to the North European plains. The pattern becomes clearer and is fully developed by 15 January. From 16 January, the trough starts to propagate equatorward and eastward over the Urals-Siberia region; and by 20 January, it reaches the Asian landmass, close to the Tibetan plateau. Moreover, it is clear from the EP flux (Nath et al., 2014) that, around mid-January, the upward component of the high latitude wave guide was very weak; it was only the downward component that could contribute to the development of the blocking high over the Urals-Siberia region. Furthermore, this development of the tropospheric WN1 pattern is consistent with the wave reflection from the stratosphere since 11 January. Moreover, the southeastward propagation and the intensification of the trough is consistent with the development of the strong blocking pattern in the Urals-Siberia region from 16 January onward. Although the reflection of the planetary waves ceases by 19 January, the blocking event persists until the last week of January with gradual eastward propagation. This extraordinary persistence had a significant impact on the extreme cold event over Eurasia and parts of China (Nath et al., 2014).

\section{Summary and discussion}

Time-lagged SVD analysis was performed to compare the covariance and correlation coefficients for the zonal mean and wave processes in the latitude band of $30^{\circ}-85^{\circ} \mathrm{N}$. We compared the 2008 winter with the composite mean pattern of six winters (2002/2003, 2004/2005, 2006/2007, 2007/2008, 2010/2011 and 2011/2012) when the downward coupling was stronger. The features were consistent in the zonal mean field, with stronger and extended (longer time scale) covariance in the lower stratospheric heights (positive lag side). For the WN1 field, the covariance was much higher (lower) for the negative (positive) lag, with a prominent peak around +15 days when the leading stratosphere coupled strongly with the troposphere. In all six winters except 2007, the basic state was partially reflective of the WN1 field; and during 2008, the reflective index was strongly negative over the Atlantic Ocean and Eurasian continent (Nath et al., 2014), favorable for the propagation of planetary waves down to the troposphere. We also analyzed the evolution of the WN1 anomaly and heat flux, both in the troposphere and stratosphere, during JFM 2008. The amplitude of the tropospheric WN1 pattern reached a maximum and was consistent with a downward wave coupling event. A stratospheric WN1 anomaly at $10 \mathrm{hPa}$ preceded a tropospheric WN1 anomaly at $400 \mathrm{hPa}$. Similarly, the negative heat flux anomaly in the stratosphere attained its maximum, with subsequent development of a strong positive heat flux anomaly in the troposphere. The tropospheric maxima clearly lagged the minima in the stratosphere.

To interpret the occurrence of the anomalous blocking high over the Urals-Siberia region due to wave reflection, we focused on the period 10-21 January 2008. The blocking anomaly developed strongly when the amplitude of the $400 \mathrm{hPa}$ WN1 pattern reached its maximum value, and the pattern continued to move westward in response to the reflection of planetary waves down to the troposphere. From the zonal-mean EP flux vectors (Nath et al., 2014), on 10 January, the high-latitude wave guide pointed vertically upward. On 13 January, the upward fluxes exhibited a gradual weakening trend, while a strengthening in the downward component was evident. This reflection/overturning was stronger on 16 January and continued until 19 January. In 3D space, wave fluxes propagated upward from the Labrador coast and reflected back to the Eurasian continent.

To illustrate the strength of the coupling between $10 \mathrm{hPa}$ and the $400 \mathrm{hPa} \mathrm{WN} 1$ fields, we plotted the heterogeneous regression pattern at negative and positive time lags. The associated regression patterns for the $10 \mathrm{hPa}$ and $400 \mathrm{hPa}$ levels at negative and positive time lags shifted westward and eastward relative to the $400 \mathrm{hPa}$ and $10 \mathrm{hPa}$ levels, respectively. This eastward phase shift of the WN1 ridge at $400 \mathrm{hPa}$ was consistent with the reflection of the WN1 field from the stratosphere. The relationship between the tropospheric WN1 field and the anomalous blocking high in the Urals-Siberia region was further established based on the daily march of the $500 \mathrm{hPa}$ geopotential height fields. From the EP flux it was quite clear that, around mid-January, the upward component of the high-latitude wave guide was very weak; it was only the downward component that could have contributed to the development of the blocking high over the Urals-Siberia region. Moreover, we found that, from 13 January onward, the WN1 pattern started to develop slowly and exhibit a meridionally elongated pattern stretching from the Bering Sea to the North European plains. The pattern developed fully by 15 
January and, from 16 January onward, the trough started to propagate equatorward and eastward over the Urals-Siberia region. And by 20 January, it reached the Asian landmass, close to the Tibetan Plateau. This development of the tropospheric WN1 pattern was due to the reflection of the WN1 field from the stratosphere from 11 January onwards.

Acknowledgements. This work was supported jointly by the National Natural Science Foundation of China (Grant Nos. 41350110331 and 41450110431) and the China Postdoctoral Science Foundation (Grant No. 2013M541010).

\section{REFERENCES}

Baldwin, M. P., and T. J. Dunkerton, 1999: Propagation of the Arctic Oscillation from the stratosphere to the troposphere. $J$. Geophys. Res., 104, 30 937-30 946.

Baldwin, M. P., and T. J. Dunkerton, 2001: Stratospheric harbingers of anomalous weather regimes. Science, 294, 581584.

Barriopedro, D., R. García-Herrera, A. R. Lupo, and E. Hernández, 2006: A climatology of Northern Hemisphere Blocking. $J$. Climate, 19, 1042-1063.

Christiansen, B., 2000: A model study of the dynamical connection between the Arctic Oscillation and stratospheric vacillations. J. Geophys. Res., 105, 29 461-29 474.

Christiansen, B., 2001: Downward propagation of zonal mean zonal wind anomalies from the stratosphere to the troposphere: Model and reanalysis. J. Geophys. Res., 106, 27 30727322.

Coughlin, K., and K. K. Tung, 2005: Tropospheric wave response to decelerated stratosphere seen as downward propagation in northern annular mode. J. Geophys. Res., 110, D01103, doi: 10.1029/2004JD004661.

Dee, D. P., and Coauthors, 2011: The ERA-Interim reanalysis: configuration and performance of the data assimilation system. Quart. J. Roy. Meteor. Soc., 137, 553-597.

Dunn-Sigouin, E., and T. A. Shaw, 2015: Comparing and contrasting extreme stratospheric events, including their coupling to the tropospheric circulation. J. Geophys. Res.: Atmos., 120, 1374-1390, doi: 10.1002/2014JD022116.

Geller, M. A., and J. C. Alpert, 1980: Planetary wave coupling between the troposphere and the middle atmosphere as a possible sun-weather mechanism. J. Atmos. Sci., 37, 1197-1214.

Hines, C. O., 1974: A possible mechanism for the production of sun-weather correlations. J. Atmos. Sci., 31, 589-591.

Hui, G., 2009: China's snow disaster in 2008, who is the principal player? International Journal of Climatology, 29, 21912196, doi: 10.1002/joc.1859.

Kodera, K., and M. Chiba, 1995: Tropospheric circulation changes associated with stratospheric sudden warmings: A case study. J. Geophys. Res., 100, $11055-11068$.

Kuroda, Y., and K. Kodera, 1999: Role of planetary waves in the stratosphere-troposphere coupled variability in the Northern Hemisphere winter. Geophys. Res. Lett., 26, 2375-2378.

Kodera, K., H. Mukougawa, and S. Itoh, 2008: Tropospheric impact of reflected planetary waves from the stratosphere. Geo- phys. Res. Lett., 35, L16806, doi: 10.1029/2008GL034575.

Kodera, K., H. Mukougawa, and A. Fujji, 2013: Influence of the vertical and zonal propagation of stratospheric planetary waves on tropospheric blockings. J. Geophys. Res.: Atmos., 118, 8333-8345.

Kodera, K., K. Yamazaki, M. Chiba, and K. Shibata, 1990: Downward propagation of upper stratospheric mean zonal wind perturbation to the troposphere. Geophys. Res. Lett., 17, 1263 1266.

Martius, O., L. M. Polvani, and H. C. Davies, 2009: Blocking precursors to stratospheric sudden warming events. Geophys. Res. Lett., 36, L14806, doi: 10.1029/2009GL038776.

Namias, J., and P. F. Clapp, 1951: Observational studies of general circulation patterns. Compendium of Meteorology, T. F. Malone, Ed., Amer. Meteor. Soc., 551-568.

Nath, D., S. Sridharan, S. Sathishkumar, S. Gurubaran, and W. Chen, 2013: Lower stratospheric gravity wave activity over Gadanki $\left(13.5^{\circ} \mathrm{N}, 79.2^{\circ} \mathrm{E}\right)$ during the stratospheric sudden warming of 2009: Link with potential vorticity intrusion near Indian sector. Journal of Atmospheric and Solar-Terrestrial Physics, 94, 54-64.

Nath, D., W. Chen, L. Wang, and Y. Ma, 2014: Planetary wave reflection and its impact on tropospheric cold weather over Asia during January 2008. Adv. Atmos. Sci., 31, 851-862, doi: 10.1007/s00376-013-3195-8.

Perlwitz, J., and H. F. Graf, 2001: Troposphere-stratosphere dynamic coupling under strong and weak polar vortex conditions. Geophys. Res. Lett., 28, 271-274.

Perlwitz, J., and N. Harnik, 2003: Observational evidence of a stratospheric influence on the troposphere by planetary wave reflection. J. Climate, 16, 3011-3026.

Perlwitz, J., and N. Harnik, 2004: Downward coupling between the stratosphere and troposphere: The relative roles of wave and zonal mean processes. J. Climate, 17, 4902-4909.

Plumb, R. A., 1985: On the three-dimensional propagation of stationary waves. J. Atmos. Sci., 42, 217-229.

Shaw, T. A., and J. Perlwitz, 2013: The life cycle of Northern Hemisphere downward wave coupling between the stratosphere and troposphere, J. Climate, 26, 1745-1763.

Shaw, T. A., J. Perlwitz, and N. Harnik, 2010: Downward wave coupling between the stratosphere and troposphere: The importance of meridional wave guiding and comparison with zonal-mean coupling. J. Climate, 23, 6365-6381.

Shaw, T. A., J. Perlwitz, and O. Weiner, 2014: Tropospherestratosphere coupling: Links to North Atlantic weather and climate, including their representation in CMIP5 models. $J$. Geophys. Res.: Atmos., 119, 5864-5880.

Tibaldi, S., and F. Molteni, 1990: On the operational predictability of blocking. Tellus A, 42, 343-365.

Treidl, R. A., E. C. Birch, and P. Sajecki, 1981: Blocking action in the Northern Hemisphere: A climatological study. Atmos. Ocean, 19, 1-23.

Uppala, S. M., D. Dee, S. Kobayashi, P. Berrisford, and A. Simmons, 2008: Towards a climate data assimilation system: Status update of ERA-Interim. ECMWF Newsletter, 115, 12-18.

Zhou, W., J. C. L. Chan, W. Chen, J. Ling, J. G. Pinto, and Y. Shao, 2009: Synoptic-scale controls of persistent low temperature and icy weather over Southern China in January 2008. Mon. Wea. Rev., 137, 3978-3991. 